\title{
The influence of green modification of lignin on the electrochemical properties of biocomposites for industrial applications
}

\author{
Rasha A. Ahmed ${ }^{1,2 *}$, Amal H. Abdel Kader ${ }^{1,3}$, Amany M. Fekry ${ }^{4}$ \\ ${ }^{1}$ Chemistry Department, Faculty of Science, Taif University, Kingdom of Saudi Arabia. \\ ${ }^{2}$ Forensic Chemistry Laboratories, Medico Legal Department, Ministry of Justice, Cairo, Egypt. \\ E-mail address: rashaauf@yahoo.com (R.A. Ahmed) \\ ${ }^{3}$ National Research Center, Cellulose and Paper Dep. Cairo, Egypt. \\ E-mail address: amalhanafy2004@yahoo.com \\ ${ }^{4}$ Chemistry Department, Faculty of Science, Cairo University, Giza-12613, Egypt. \\ E-mail address: hham4@hotmail.com
}

\begin{abstract}
It's a report on a novel approach; preparation and electrochemical properties of modified lignin. Wax and starch were used as natural, green adhesives for enhancing the electrical resistivity of lignin in acidic medium, forming eco-friendly high insulator biocomposite. Scanning electron microscopy (SEM) was used to characterize the fabricated biocomposite. The modified lignin was characterized using Fourier transform infrared (FTIR), while the electrochemical behavior was examined by cyclic voltammetry (CV) and electrochemical impedance spectroscopy (EIS). The innovative approach described in this work provides a promising eco- friendly method for lignin modification with highly electrical resistivity and stability with time.
\end{abstract}

Keywords: electrical characterization; insulators; green binder; lignin.

*Corresponding author at: Chemistry Department, Faculty of Science, Taif University, Saudi Arabia. Tel.: +966 0562805809.

\section{Council for Innovative Research}

Peer Review Research Publishing System

Journal: Journal of Advances in Chemistry

Vol. 10, No. 5

editorjaconline@gmail.com

www.cirjac.com 


\section{Introduction}

Dynamic development of technologies for synthesis of new raw materials that are eco-friendly has been driven by the need to obtain products of specific unique properties. However, the possibility of using waste materials can achieve this goal [1].

Although, lignins are one of the most abundant macromolecules in plant tissues, and a feasible raw material for many valuable substances such as polymer fillers, complexing agents [2, 5], this renewable biomass resource is wasted from paper making and sugar production processes, being simply burnt and used as an energy source. It was reported that, lignin polymers have been widely applied in macromolecule fields, as being more efficient than petroleum-based polymers, which contain phenol formaldehyde, a highly toxic chemical, and touted for avoiding environmental pollution [6-7].

Various efforts have been made to better understand the relationship between structure and properties of these macromolecules to find out higher application values [8]. It is well known that, Lignin has an irregular structure with a highly condensed cross-linked polymer network providing a biomass with high mechanical strength as well as super rigidity to resist external forces [9-11]. Hindered phenolic groups of lignin can act as stabilizers in reactions induced by oxygen and its reactive species and conditions low down of ageing of composites and biological systems. The presence of other functional groups and bonds in lignin structure, such as alcohol hydroxyl, aromatic units, and ether linkages, help in coupling with other organic and inorganic materials by side-chain selection and graft copolymerization [12-13]. However, the presence of abundant methyl groups makes lignin less reactive and poor in cross-linking [14]. As a result, utilization of lignin is always challenging and frequently involves modification or coupling with other macro-molecular materials [15-16]. Common techniques for lignin modification use chemical, physical, or biological methods to increase its reactivity [13].

Natural glues, Starch, have been used in a wide variety of applications as binding agent. Addition of starch can adjust viscosity easily and reduce material costs [17]. Owning to its polar character, Starch provides high affinity to cellulose and many porous substrates [18]. In addition, Commercial wax, natural additive, can be used as flow improver, increase in viscosity due to wax crystallization, which in turn could increase the composite resistance to plastic deformation [19, 20].

Therefore, the aim of this study was to prepare and characterize natural biocomposite, produced from modified lignin with natural additives for the first time. Different techniques were applied to study the morphological and the electrochemical properties of the modified biocomposite intended for further use as ecofriendly and high stable insulators.

\section{Experimental procedures}

\subsubsection{Reagent and materials}

Black liquor produced from industrial kraft pulping of eucalyptus wood (E. globulus), and sawdust waste (SDW) were provided by wood and furniture factories (Egypt). Corn starch and Wax were purchased from Wako Pure Chemicals Industries Ltd. (Osaka, Japan). Lignin extraction from black liquor described in the schematic diagram fig.1, was carried by precipitation with acid according to the previously described procedure [21]. All reagents were used as received and the solutions were prepared using deionized water.

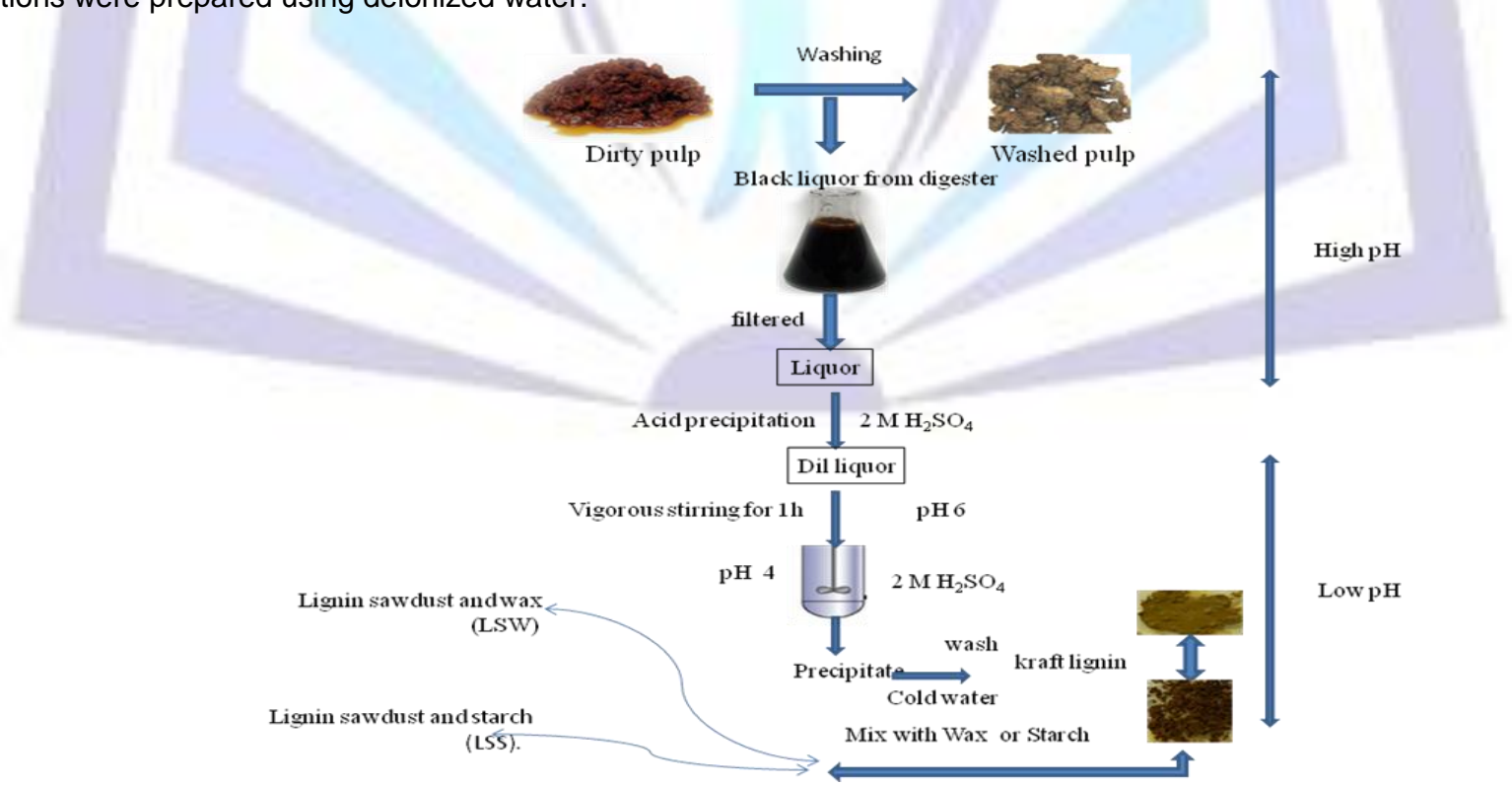

Fig. 1. Schematic diagram for lignin separation and preparation of the biocomposites. 


\subsubsection{Preparation of lignin modified electrodes}

Three samples using lignin (LS) were prepared by mixing the desired composite with fine sawdust waste and natural additives wax or starch in a proportion of $3: 1(\mathrm{w} / \mathrm{w})$, giving two modified samples (LSW) and (LSS), respectively. The body of the electrode consists of a Teflon tube, $9 \mathrm{~cm}$ in length, drilled from side to side by a brass stem to make the electrical contact [22]. One of the extremities of the brass stem was lowered toward the extremity of the Teflon tube in order to produce a cavity with a diameter of $5 \mathrm{~mm}$ where the biocomposite was added while the other extremity was used for the connection to the potentiostat.

\subsection{Apparatus}

\subsubsection{Electrochemical measurements}

Voltammetric measurements were carried out with a potentiostat/galvanostat (PGSTAT-73022) Auto lab. Analysis of variance (ANOVA) was used to compare the mean differences of the samples. A conventional three-electrode system was adopted. The working electrode was the above described empty Teflon electrode, while the auxiliary and reference electrodes were platinum wire and $\mathrm{Ag} / \mathrm{AgCl}, \mathrm{KCl}$ (sat), respectively. All electrochemical measurements were performed in a $30 \mathrm{~cm}^{3}$ electrochemical cell at room temperature. All $\mathrm{pH}$ measurements, when necessary, were done using $\mathrm{pH}-\mathrm{meter}$. EIS measurements were done at an open circuit potential with an applied $10 \mathrm{mV}$ sinusoidal perturbations in the $100 \mathrm{kHz}$ to $0.1 \mathrm{mHz}$ frequency range, taking 7 steps per decade. The tests were carried out in $0.1 \mathrm{M} \mathrm{HNO}_{3}$.

\subsection{2 .Scanning electron microscope}

SEM images of the composites of lignin, lignin with wax or starch were recorded using gold coated samples on (Philips, XI 30) Scanning Electron Microscope equipped with Schottky electron gun. Mixture contained 8 wt.\% of wax or starch, which corresponded to the 0.72 wt. $\%$ in lignin.

\subsection{3 .FTIR - Fourier transform infrared spectroscopy}

The FTIR spectra were registered using brucker equipment, briefly: it used $1 \mathrm{mg}$ of sample to $50 \mathrm{mg}$ of dried $\mathrm{KBr}$; the mixture was macerated in a mortar of agate and pressed into $13 \mathrm{~mm}$ diameter pastillator at a pressure of 7 metric tons. In the spectral range of $4000-400 \mathrm{~cm}^{-1}$, the resolution was $4 \mathrm{~cm}^{-1}$ in 64 scans.

\section{Results and discussion}

\subsection{Surface morphology}

\subsubsection{Scanning Electron Microscopy (SEM)}

Firstly, the unmodified lignin-sawdust was prepared and then modified with natural additives as wax and starch. The modification was performed to improve the electrical resistivity by increasing the density and filling lignin porous structure. The SEM was done to show the morphology and the interference between composites at different magnifications. Fig. 2(A) shows the SEM images of the lignin samples (LS), where large number of pores and cavities were observed. The low cross linking and porous structure of LS result in electric conductivity. Fig. 2(B, C), shows a relatively mild mixing of wax and starch with lignin, respectively. SEM of LSW and LSS samples reveals that both samples are dense compact layers. The good network of interconnected pores improves the electric resistivity of LS owning to the presence of wax and starch which act as a great gap fillers. In addition, these fillers also increase adhesion between lignin and sawdust wastes. 

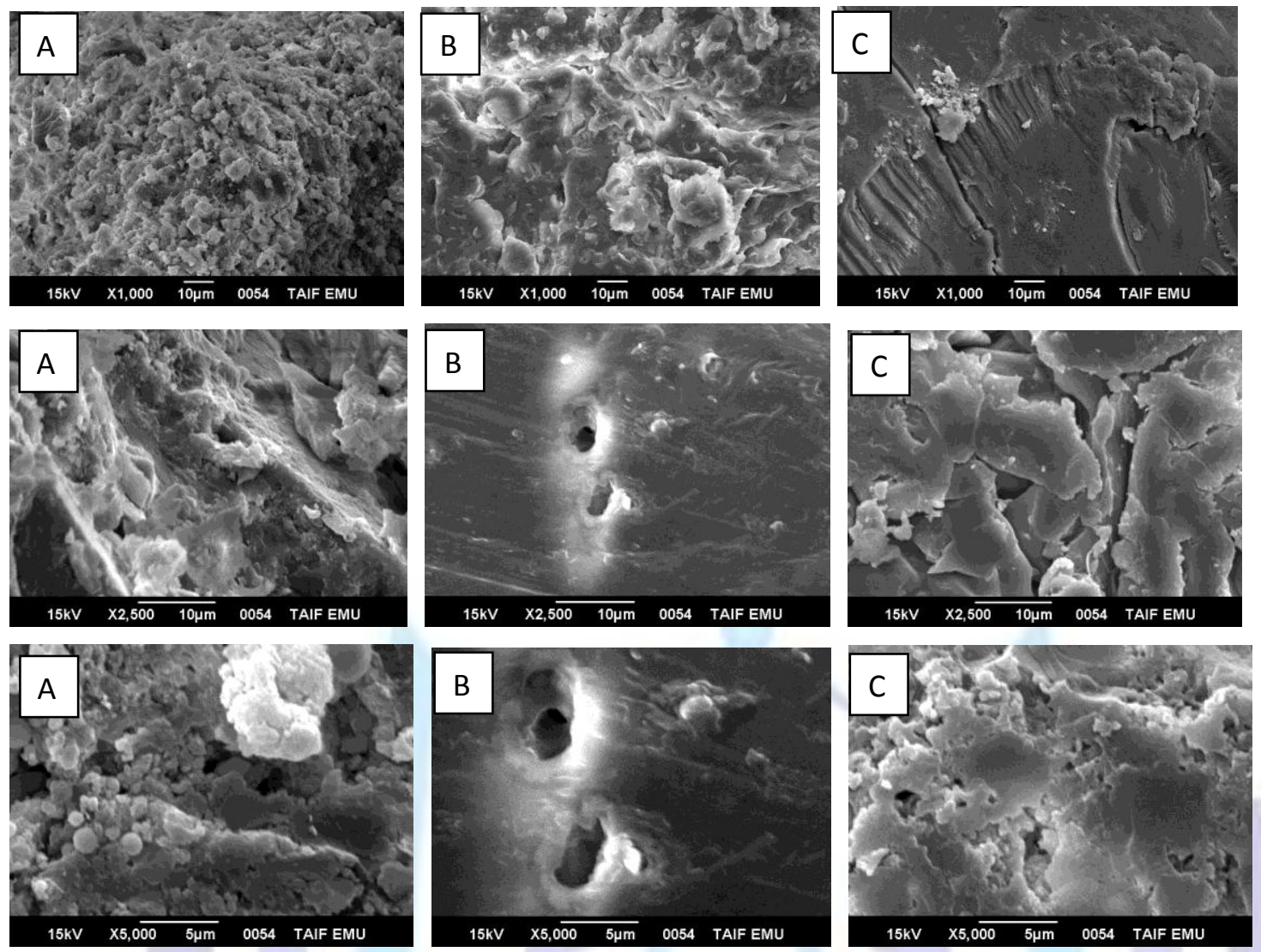

Fig.2. SEM images of (a) unmodified and modified lignin with (b) wax and (c) starch. (magnifications; X 1000, X 2500, X 5000).

\subsubsection{Comparison of IR Spectra}

A full, detailed IR transmission spectrum for the three samples was obtained, and is presented in Fig. 3, the LS spectra is also shown expanded to clarify the detail it contain. The IR spectrum of LS Fig. 3(a) shows, the appearance of bands at $1692-1419 \mathrm{~cm}^{-1}$ for the aromatic skeletal vibration of the LS, The characteristic bands of lignin were assigned according to the literature, as shown in Table 1. In contrast, if we look at the IR spectra of LSW Fig. 3(b), significant features seen include: Appearance of a band at $1029 \mathrm{~cm}^{-1}$ which can be assigned to C-O stretching. Progression of weak band at 1041 $\mathrm{cm}^{-1}$ for $\mathrm{C}-\mathrm{OH}$ stretch is noticed. Other frequency present at $708 \mathrm{~cm}^{-1}$ for $\mathrm{CH}_{2}$ rocking assigned to wax structure. Spectrum of LSS Fig. 3(c), for the modified lignin with starch was obtained. The absorption region at $1029 \mathrm{~cm}^{-1}$ relates to $\mathrm{C}-\mathrm{C}$ and $\mathrm{C}-\mathrm{O}$ stretching modes of the polysaccharide backbone [23, 24]. Appearance of a band at $1356 \mathrm{~cm}^{-1}$ assigned to bending modes of $\mathrm{O}-\mathrm{C}-\mathrm{H}, \mathrm{C}-\mathrm{C}-\mathrm{H}$, and $\mathrm{C}-\mathrm{O}-\mathrm{H}$ angles [24]. The band at $3450 \mathrm{~cm}^{-1}$, which is attributed to hydroxyl group stretching, had a higher intensity of starch than LS.

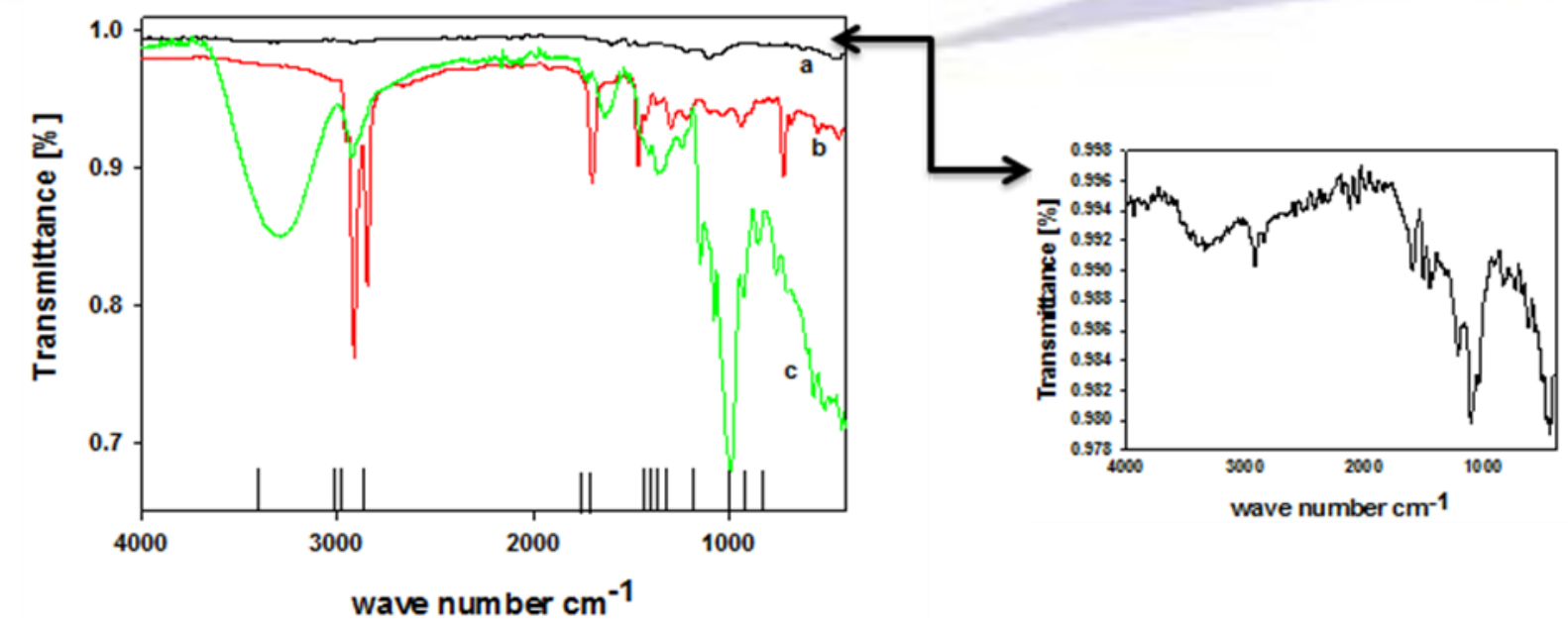

Fig. 3. FT-IR spectra of (a) unmodified lignin, and modified lignin with (b) wax and (c) starch. 
Table 1. Lists of assignment for different IR bands of LS, LSW, LSS samples

\begin{tabular}{ll}
\hline Maximum band position $\left(\mathbf{c m}^{-1}\right)$ & Band origin \\
\hline $3450-3694$ & $\mathrm{OH}$ stretching $(\mathrm{H}$ - bonded $)$ \\
$2924-2926$ & $\mathrm{CH}$ stretching of methyl or methylene group. \\
2858 & $\mathrm{CH}$ vibration of methyl of methoxy group. \\
1457.9 & $\mathrm{CH}$ stretching of methyl or methylene group. \\
$1417-1419$ & $\mathrm{CH}$ vibration of methyl group. \\
$1029-1041$ & OH stretching of primary alcohol. \\
844 & Aromatic C-H out of plane bending. \\
\hline
\end{tabular}

\subsection{Electrochemical study}

\subsubsection{Electrical resistivity of modified lignin biocomposite}

Cyclic voltammetry measurements were performed over a potential range of -2 to $2 \mathrm{~V} / \mathrm{s}$ ) to examine the electrical resistivity of lignin in presence and absence of natural additives. Fig. 4(A) shows the cyclic voltammogram of lignin and sawdust in $0.1 \mathrm{~mol} \mathrm{~L}^{-1} \mathrm{HNO}_{3}$ at $288 \mathrm{~K}$. One anodic broad peak current at $-0.12 \mathrm{~V}$ with a high charging current during the potential sweep is observed. This attributed to the flow of electric charges through lignin particles (blank), which in turn increases the electric conductivity and decreases resistivity of the sample. The flow of electric charges is related to the contribution of high pore diameter of LS and the conjugated structure of lignin. However, Fig. 4(B, C) shows the cyclic voltammogram of modified lignin-sawdust with wax and starch, respectively; in $0.1 \mathrm{~mol} \mathrm{~L}^{-1} \mathrm{HNO}_{3}$ at $288 \mathrm{~K}$. It was found that modified lignin with starch shows higher electrical resistance than that with wax due to the different specific characteristics of each blend, such as chemical structure, molecular weight and their conformation. On the other hand, Fig. 4(B, C) show the shrinking of the anodic current peaks. This behavior was attributed mainly to additives which fill the porous layers of lignin, and retarded the movement of electric charges and thus intern, decreases the conductivity and increases the insulation behavior of the biocomposite. These data comes in a good agreement with the SEM images.

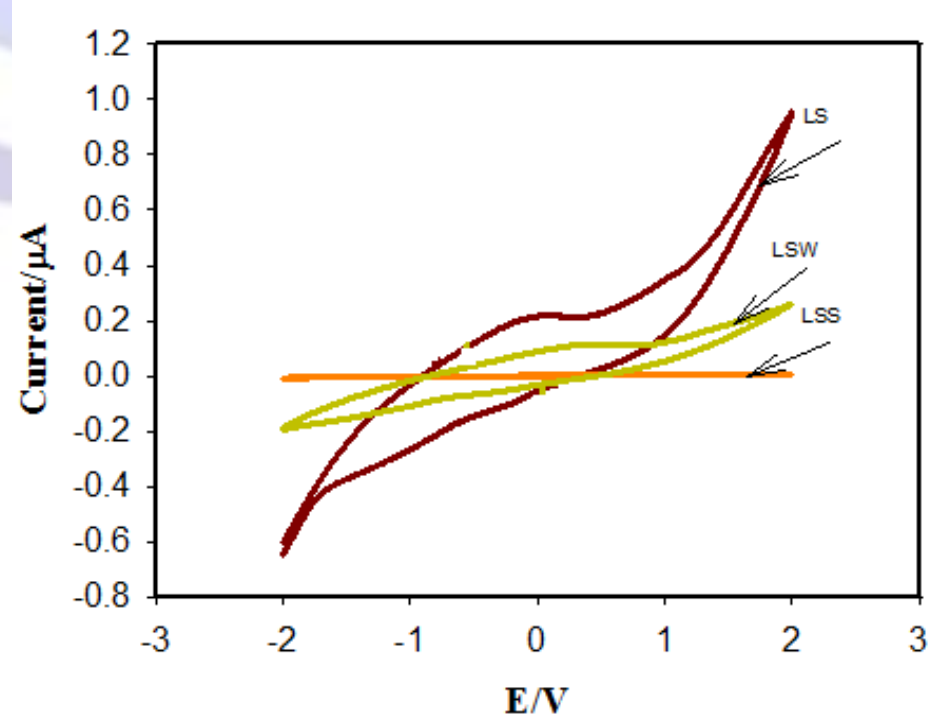

Fig. 4. Cyclic voltammograms of unmodified lignin (LS), LSW, and LSS in acid medium at $288 \mathrm{~K}$. 


\subsection{Impedance measurements}

\subsubsection{Effect of additives}

To confirm the effectiveness of wax and starch on the electrical resistivity of lignin composite and to show their stability with time, electrochemical impedance were investigated in absence and presence of additives. Fig.5 (a,b) show both Bode and Nyquist plots, respectively, of lignin with immersion time, in $0.1 \mathrm{~mol} \mathrm{~L}^{-1} \mathrm{HNO}_{3}$ at $288 \mathrm{~K}$. As shown in Fig.5a, phase diagram is so small with phase angle maximum $\left(\theta_{\max }\right) \sim 30^{\circ}, \theta_{\max }$ decreases sharply then gradually increases with immersion time till $18 \mathrm{~h}$. This means that the lignin composite is electrically conducting due to its porous layers. As there is no sharp increase in conductivity with time but still stable for both phase angle maximum and impedance values after immersion for $6 \mathrm{~h}$. This can be confirmed from Nyquist plot (Fig.5b), the arc diameter decreases with increasing immersion time, so that impedance value decreases.

To account for the electrical resistivity of the biocomposites, an equivalent electrical circuit model, as is given in Fig. $5 \mathrm{c}$, was utilized to simulate the effect of addition of wax and starch to lignin and to analyze the Nyquist and Bode plots. Fitting of the plots requires a two-time constant equivalent electrical circuit. In this model, $R_{s}$ refers to solution resistance, $R$ and $Z_{w}$ refer to resistance and Warburg impedance of the two formed phases which act as two insulating layers. $Z_{w}$ indicates a diffusion controlled process [25]. For the two layers, there is a corresponding two parallel constant-phase elements $\left(\mathrm{C}_{1}\right.$, and $\mathrm{C}_{2}$ ), a constant-phase element (CPE) was used instead of the ideal capacitance to account for heterogeneity and roughness of the surface [26]. The impedance of a phase element is given by $Z_{\mathrm{CPE}}=\left[C(\mathrm{jw})^{\alpha}\right]^{\mathrm{n}-1}$, where $-1 \leq \alpha \leq 1$. The value of $\alpha$ is due to roughness and surface defects. The resistance and capacitance values of the two layers are given in Table 2.
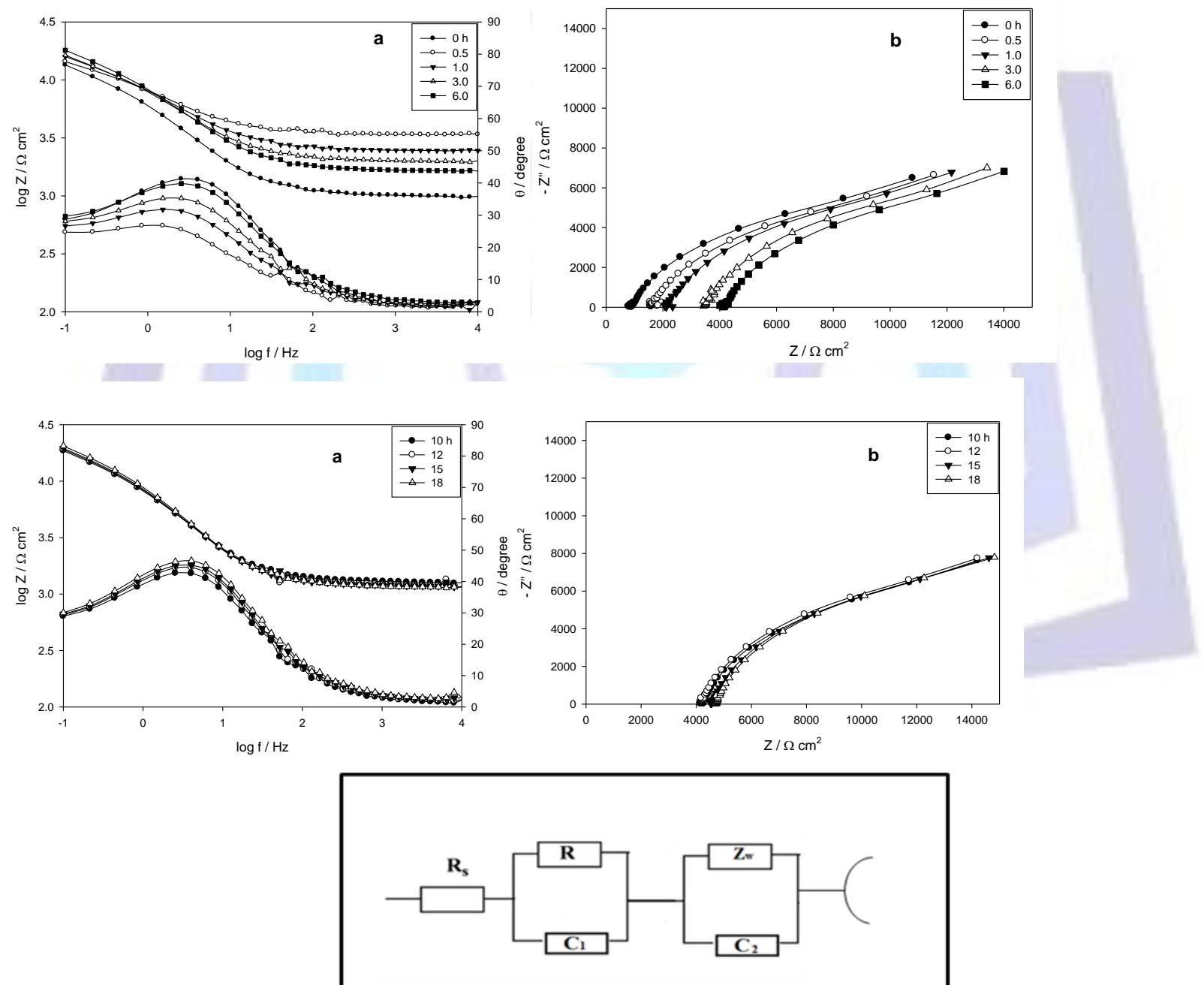

Fig. 5. (a) Bode and (b) Nyquist plots of unmodified lignin (L) in acid medium at $288 \mathrm{~K}$ with immersion for $18 \mathrm{~h}$. (c) Two time constant equivalent circuit model used for fitting. 
Table 2: Kinetic parameters derived from EIS plots of samples LS, LSW, LSS

\begin{tabular}{|c|c|c|c|c|c|c|c|c|}
\hline Sample & $\begin{array}{c}\text { Time } \\
\text { (h) }\end{array}$ & $\begin{array}{c}R \\
\left(k \Omega \mathrm{cm}^{2}\right)\end{array}$ & $\begin{array}{c}\mathrm{C}_{1} \\
\left(\mu \mathrm{F} \mathrm{cm}^{-2}\right)\end{array}$ & $\alpha_{1}$ & $\begin{array}{c}\mathrm{Z}_{\mathrm{W}} \\
\left(\mathrm{k} \Omega \mathrm{cm}^{2} \mathrm{~S}^{-1 / 2}\right)\end{array}$ & $\begin{array}{c}\mathrm{C}_{2} \\
\left(\mu \mathrm{F} \mathrm{cm}^{-2}\right)\end{array}$ & $\alpha_{2}$ & $\begin{array}{c}\mathbf{R}_{\mathrm{s}} \\
\left(\Omega \mathrm{cm}^{2}\right)\end{array}$ \\
\hline & 0.0 & 397 & 80.5 & 0.68 & 45.1 & 112.1 & 0.51 & 208 \\
\hline & 0.5 & 672 & 77.3 & 0.69 & 50.7 & 108.4 & 0.53 & 131 \\
\hline & 1.0 & 747 & 70.5 & 0.68 & 67.3 & 105.3 & 0.56 & 190 \\
\hline & 3.0 & 850 & 61.5 & 0.67 & 74.1 & 103.2 & 0.54 & 177 \\
\hline \multirow[t]{9}{*}{ LS } & 6.0 & 1139 & 60.3 & 0.76 & 80.3 & 101.4 & 0.55 & 251 \\
\hline & 10.0 & 1243 & 59.7 & 0.69 & 89.4 & 100.3 & 0.55 & 250 \\
\hline & 12.0 & 1458 & 58.0 & 0.73 & 95.2 & 98.7 & 0.56 & 248 \\
\hline & 15.0 & 1556 & 57.3 & 0.75 & 105 & 95.2 & 0.57 & 253 \\
\hline & 18.0 & 1635 & 56.1 & 0.73 & 114 & 94.3 & 0.61 & 254 \\
\hline & 0.0 & 511 & 58.5 & 0.66 & 70.3 & 103.5 & 0.45 & 974 \\
\hline & 0.5 & 723 & 45.6 & 0.66 & 83.6 & 101.7 & 0.46 & 3547 \\
\hline & 1.0 & 878 & 45.3 & 0.68 & 89.5 & 99.8 & 0.47 & 2503 \\
\hline & 3.0 & 989 & 45.0 & 0.65 & 94.4 & 97.6 & 0.49 & 1967 \\
\hline \multirow[t]{9}{*}{ LSW } & 6.0 & 1340 & 43.2 & 0.70 & 113 & 96.7 & 0.50 & 947 \\
\hline & 10.0 & 1468 & 42.1 & 0.68 & 121 & 95.0 & 0.49 & 1202 \\
\hline & 12.0 & 1576 & 41.1 & 0.71 & 136 & 94.1 & 0.52 & 1105 \\
\hline & 15.0 & 1700 & 41.0 & 0.72 & 145 & 92.2 & 0.53 & 1132 \\
\hline & 18.0 & 1865 & 40.9 & 0.74 & 163 & 90.0 & 0.54 & 1167 \\
\hline & 0.0 & 514 & 44.0 & 0.71 & 90.1 & 90.5 & 0.54 & 822 \\
\hline & 0.5 & 747 & 41.2 & 0.73 & 111 & 87.1 & 0.57 & 309 \\
\hline & 1.0 & 875 & 40.1 & 0.78 & 127 & 83.5 & 0.57 & 205 \\
\hline & 3.0 & 1101 & 39.4 & 0.75 & 138 & 80.6 & 0.58 & 234 \\
\hline \multirow[t]{5}{*}{ LSS } & 6.0 & 1433 & 39.0 & 0.73 & 156 & 79.3 & 0.59 & 250 \\
\hline & 10.0 & 1670 & 38.7 & 0.78 & 169 & 76.1 & 0.61 & 251 \\
\hline & 12.0 & 1859 & 38.5 & 0.75 & 175 & 75.0 & 0.61 & 249 \\
\hline & 15.0 & 2111 & 38.0 & 0.74 & 189 & 74.7 & 0.62 & 251 \\
\hline & 18.0 & 2356 & 37.9 & 0.73 & 203 & 74.0 & 0.62 & 250 \\
\hline
\end{tabular}

Fig. $6 \mathrm{a}, \mathrm{b}$ shows both Bode and Nyquist plots of modified lignin with wax, with immersion time in $0.1 \mathrm{~mol} \mathrm{~L}^{-1} \mathrm{HNO}_{3}$ at 288 K. Fig.6a shows that the phase diagram changed with phase angle maximum $\sim 50^{\circ}$. The impedance values increase with increasing time then become stable, however with higher values than those of lignin. The same is observed for $Z_{w}$ values which increase with increasing time indicating increasing diffusion controlled process with time. This is also clear from Nyquist plot (Fig. 6b). The same model in Fig. 5c used to fit Fig $6(a, b)$ and fitting data is given in Table 2. Fig. 7(a, b) show both Bode and Nyquist plots of modified lignin with starch, with immersion time in $0.1 \mathrm{~mol} \mathrm{~L}^{-1} \mathrm{HNO}_{3}$ at $288 \mathrm{~K}$. From the phase diagrams, the phase angles approaching $60^{\circ}$ indicate a highly electrical resistivity typical for a compact passive composite. Fitting data are also given in Table 2 with the same model shown in Fig. 5c. Adding starch to lignin changes phase diagram shape and leads to an increase in impedance values. The results in Table 2, imply that the lignin particles packed more intimately in presence of wax and starch, therefore reducing the amount of possible poor conducting air gaps in the biocomposite. These results in decreasing the inter particle contact which retards the flow of electricity. The resistance properties of lignin biocomposite are closely related to the additives' structure. Lignin biocomposite could be considered a two-phase system including disordered carbon and turbostratic crystallites with large wax or starch layers, which is responsible for the electrically resistive phase of the material. 

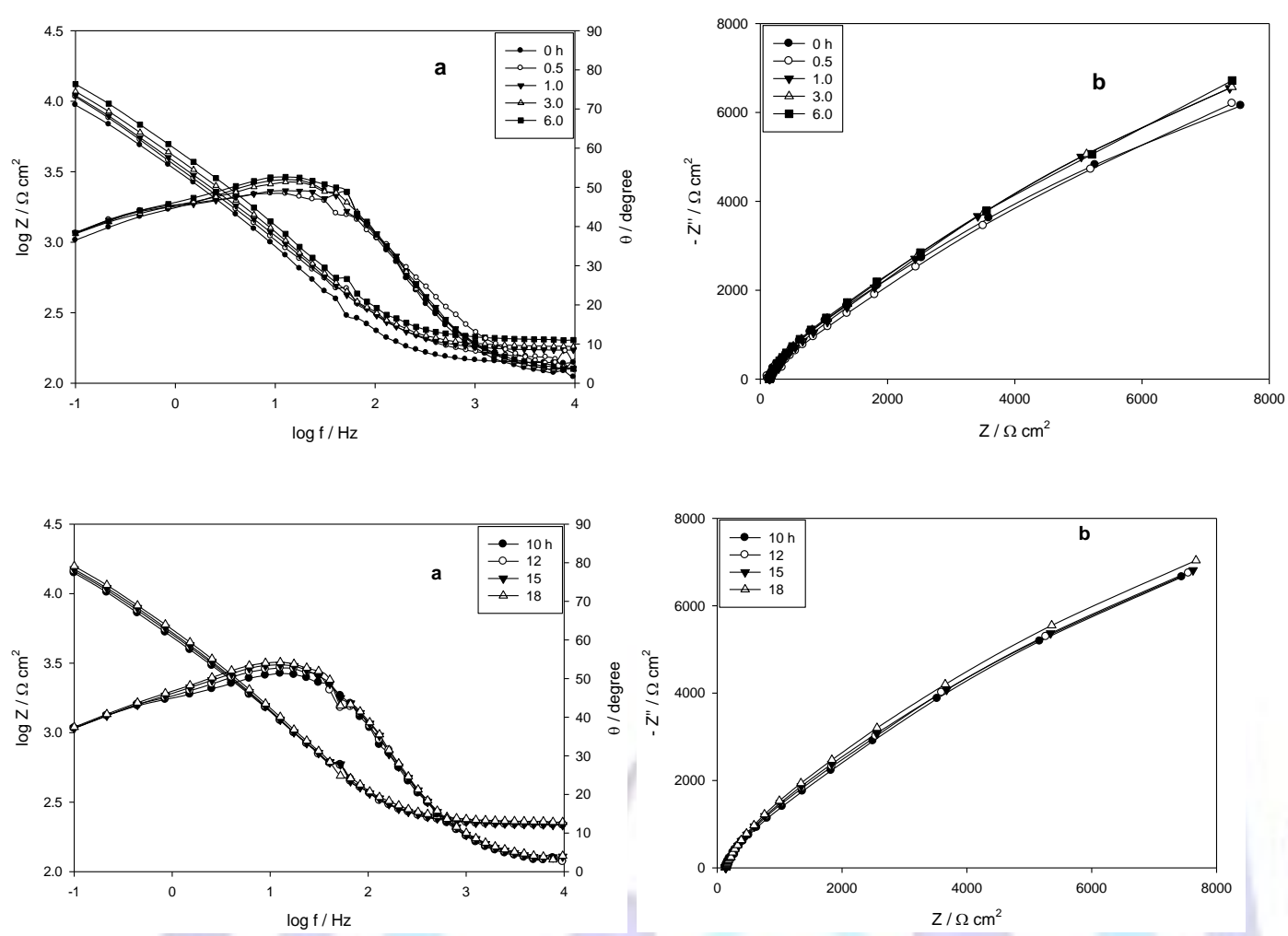

Fig. 6. (a) Bode and (b) Nyquist plots of modified lignin with wax (LSW) in acid medium at $288 \mathrm{~K}$ with immersion for $18 \mathrm{~h}$.
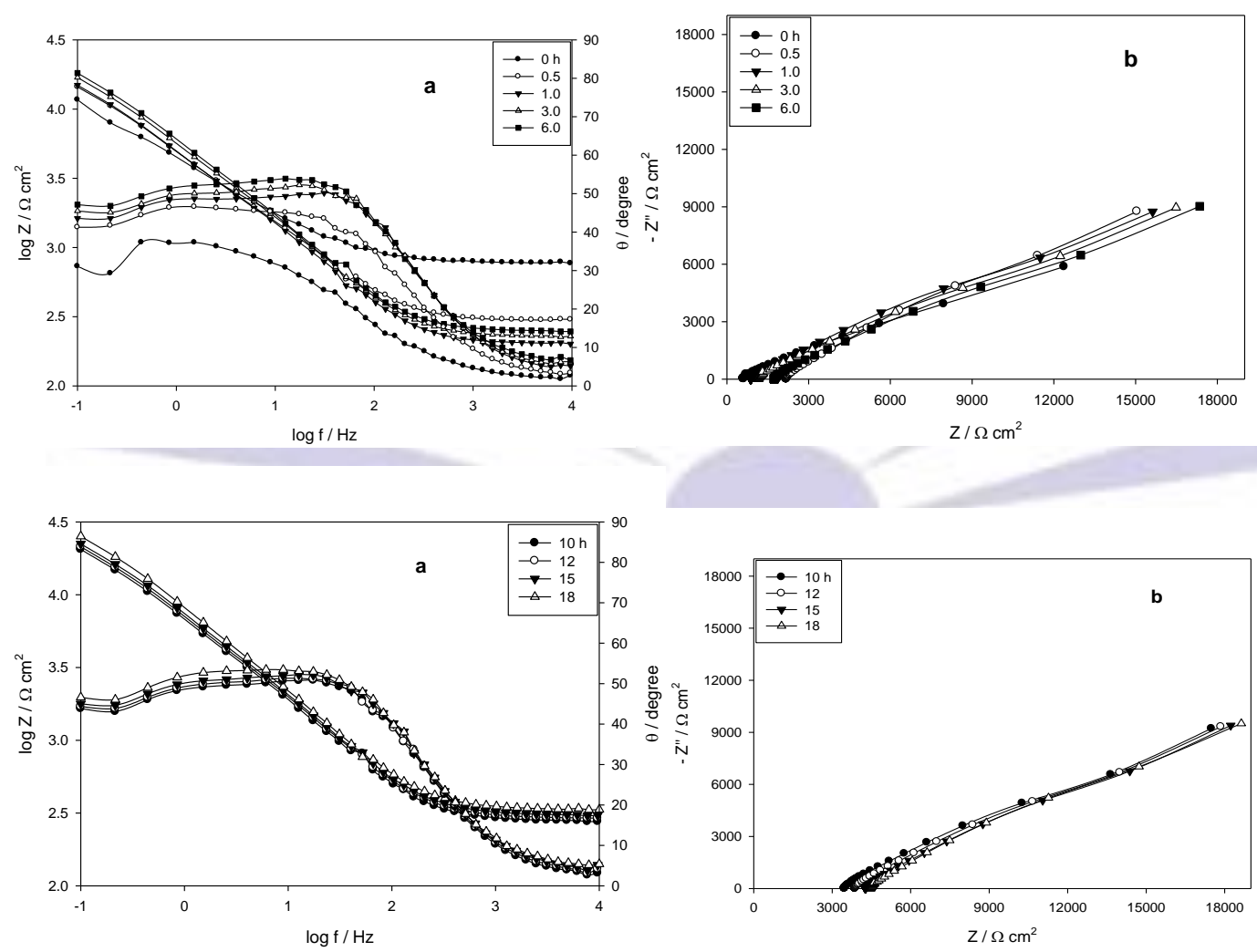

Fig. 7. (a) Bode and (b) Nyquist plots of modified lignin with starch (LSS) in acid medium at $288 \mathrm{~K}$ with immersion for $18 \mathrm{~h}$. 


\subsubsection{Potentiodynamic polarization}

Polarization behavior of tested modified lignin was followed by scanning from - 0.5 to $2.0 \mathrm{~V}$ vs. SCE (Fig. 8 ) after $2 \mathrm{~h}$ of immersion using potentiodynamic polarization measurements at a scan rate of $1.0 \mathrm{mV} \mathrm{s}^{-1}$ in acidic medium. Prior to the potential scan, the electrode was left under open circuit conditions in the respective solution for $2 \mathrm{~h}$ until a steady free corrosion potential $\left(E_{s t}\right)$ value was recorded. The corrosion potential $\left(E_{\text {corr }}\right)$ and current density ( $\left.i_{\text {corr }}\right)$ were calculated by Tafel extrapolation method for the cathodic branches of the polarization curves [27]. As an illustration of the relative stability of the modified lignin composite in acidic medium, $\mathrm{i}_{\text {corr }}$ values are found to decrease and $\mathrm{E}_{\text {corr }}$ values shifts positively in the same order as obtained previously from open circuit potential and impedance measurements as follows: LSS $>$ LSW $>$ LS. According to the electrochemical parameters ( $i_{\text {corr }}, E_{c o r r}$ ) given in Table 3 , it is confirmed that blends lead to protection of lignin. But it can be seen that sample containing wax or starch have lower levels of $i_{\text {corr }}$ compared to unmodified lignin. This means that by introducing wax or starch to lignin, resistivity increased. Additionally, the incorporation of wax or starch inside lignin particles decreases cathodic Tafel slope while increasing the anodic one. Moreover, the value of $i_{\text {corr }}$ is much lower for starch composite which agrees with EIS results. Generally, it can be clearly seen that the conductivity of lignin decreased drastically in presence of starch more than in presence of wax.

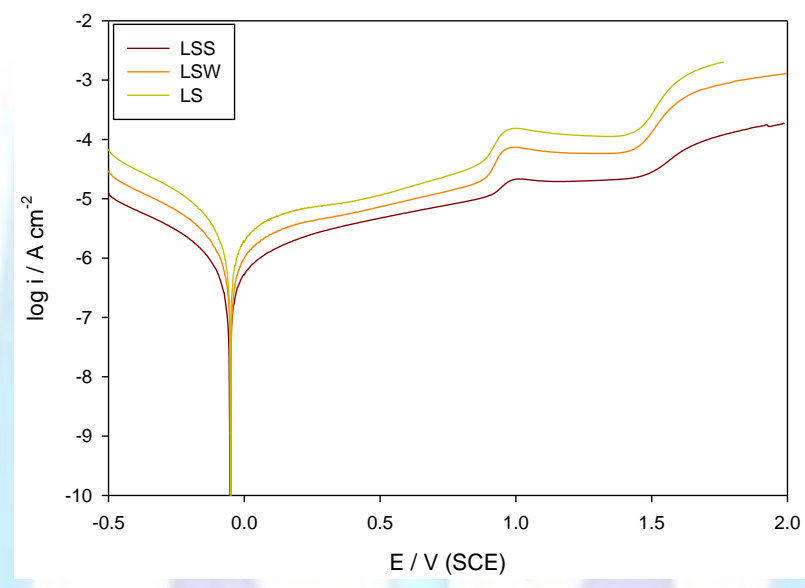

Fig. 8. Polarization scans for (a) unmodified lignin (L), (b) LSW, and (c) LSS after immersion for $18 \mathrm{~h}$ in acid medium at $288 \mathrm{~K}$.

Table 3: Polarization parameters of samples LS, LSW, LSS

\section{Conclusions}

Advanced biocomposite consists of lignin and natural additives may be novel biomaterials of important practical significance.Their attractive features for practical uses are their electrical resistivity and stability with time. The effectiveness of the modification was confirmed by results of SEM, FTIR and electrochemical analysis. As evidenced by morphological analysis, the addition of wax or starch to lignin significantly affects the homogeneity and porosity of the biocomposite. From the electrochemical analysis, the electrical resistivity of lignin increased drastically on the addition of wax and starch. This study suggests that the modified lignin can be exploited as an insulator. Finally, the results have confirmed the need for working on natural biocomposites of this type because of their potential use in science and industry. 


\section{Acknowledgements}

We gratefully acknowledge chemistry department (University of Taif, kingdom of Saudi Arabia) for financial support to carry out the above investigations.

\section{References}

[1] Pereira CL, Savastano H, Pa. J, Santos SF, Borrachero MV, Mon. J, et al. Use ofhighly reactive rice husk ash in the production of cement matrix reinforcedwith green coconut fiber. Ind Crops Prod 49 (2013) 88-96.

[2] D. Feldman, in: T.Q. Hu (Ed.), Chemical Modification, Properties, and Usage of Lignin, Kluwer, Academic/Plenum Publishers, New York, (2002) 81-100.

[3] D.K. Setua, M.K. Shukla, V. Nigam, H. Singh, G.N. Mathur, Lignin reinforced rubber composites. Polym. Compos.21(2000) 988-995.

[4] T.Q. Hu, Chemical Modification, Properties, and Usage of Lignin, Kluwer Aca-demic/Plenum Publishers, New York, 2002.

[5] L. Glasser, S. Sarkanen, Lignin: Properties and Materials, American ChemicalSociety, Washington, DC, 1989.

[6] Sun, X.S., Bian, K., Shear strength and water resistance of modified soy proteinadhesives. J. Am. Oil Chem. Soc.76 (1999) 977-980.

[7] Alonso, M.V., Oliet, M., Rodriguez, F., Garcia, J., Gilarranz, M.A., Rodriguez, J.J., Modification of ammonium lignosulfonate by phenolation for use in phenolicresins. Bioresour. Technol. 96 (2005)1013-1018.

[8] W. Glasser, S.S. Kelley, in: H.F. Mark, N.M. Bikales, C.G. Overberger, G.Menges (Eds.), Encyclopedia of Polymer Science and Engineering, vol. 8,Wiley, New York, 1987, 795.

[9] Nimz, H., Beech lignin - proposal of a constitutional scheme.Angew. Chem.Int. Edit. 13(1974) 313-321.

[10] Fengel, D., Wegener, G., Wood - Chemistry, Ultrastructure, Reactions. DeGruyter, Berlin 1984.

[11] Lai, Y., Sarkanen, K., Lignins - Occurrence, formation, structure and reactions.Wiley-Inter-Science, New York 1971.

[12] Malutan, T., Nicu, R., Popa, V.I., Contributionto the study of hydroxymetylationreaction of alkali lignin.BioRes 3 (2008)13-20.

[13] Ungureanu, E., Ungureanu, O., Capraru, A.M., Popa, V.I., Chemical modificationand characterization of straw lignin.Cell. Chem. Technol. 43 (2009) 263-269.

[14]Okamoto, T., Takeda, H., Funabiki, T., Takatani, M., Hamada, R., Fundamental studies on the development of ligninbased adhesives 1.Catalytic demethylation of anisole with molecular oxygen. React. Kinet.Catal.Lett. 58 (1996) 237242.

[15] Alonso, M.V., Oliet, M., Rodriguez, F., Garcia, J., Gilarranz, M.A., Rodriguez, J.J., Modification of ammonium lignosulfonate by phenolation for use in phenolicresins. Bioresour. Technol. 96 (2005) 1013-1018.

[16] Batubenga, D.B., Pizzi, A., Stephanou, A., Cheesman, P., Krause, R., Isocyanatephenolics wood adhesives by catalytic acceleration of copolymerization. Holz-forschung 49 (1995) 84-86.

[17] Plath, L., Die Rolle von Starkeproduktenbei der Verleimung von HolzwerkstoffenmitKunstharz-Leimen. Starch-Starke 24 (9) (1972), 306-312.

[18] Lazarus, D.M., Adhesives based on starch. In: Allen, K.W. (Ed.), Adhesion, vol.7. Applied Science, London, (1983)197-219.

[19] Damm KW, Abraham J, Butz T, Hildebrand G, Riebesehl G. AsphaltverflüssigerAls 'IntelligenterFüller' Für Den Heisseneinbau-EinNeuesKapitel In Der Asphaltbauweise. Bitumen, 1(2002)19-24.

[20] Damm KW, Abraham J, Butz T, Hildebrand G, Riebesehl G. AsphaltverflüssigerAls 'IntelligenterFüller' Für Den Heisseneinbau-EinNeuesKapitel In Der Asphaltbauweise. Bitumen 1 (2002) 55-61.

[21] Tamminen T., Vuorinen T., Tenkanen M., Hortling B. Analysis of lignin and lignin carbohydrate complexes isolated from black liquor. 8th International Symposium on Wood and Pulping Chemistry, Helsinki, Finland, 2 (1995), 297302.

[22] Rasha A. Ahmed, Amal H. Abdel Kader, Effect of additives on electrical resistivity of pulp black liquor- sawdust blends, IJMER, 3 (2013) 183-188.

[23] Wilson, R.H. and Belton, P.S. A Fourier-transform infrared study of wheat starch gels. Carbohydr. Res.180(1988) 339-344. 
[24] Bellon-Maurel, V., Vallat, C., and Goffinet, D. Quantitative analysis of individual sugars during starch hydrolysis by FTIR/ATR spectrometry.part I: Multivariate calibration study--repeatability and reproducibility. Appl. Spectrosc. 49 (1995) 556-562.

[25] Fekry MA, Fatayerji MZ. Electrochemical corrosion behavior of AZ91D alloy in ethylene glycol, Electrochimica Acta. 54 (2009) 6522.

[26] Fekry MA. The influence of chloride and sulphate ions on the corrosion behavior of Ti and Ti-6Al-4V alloy in oxalic acid. Electrochimica Acta.54(2009) 3480.

[27] Fekry AM, Ghoneim AA, Ameer MA. Electrochemical impedance spectroscopy of chitosan coated magnesium alloys in asynthetic sweat medium. Surface coatings and technology. 238 (2014)126-132. 